\title{
Observations on the efficiency of dystrophic muscle in vitro
}

\author{
WILLIAM W. HOFMANN AND ERNST O. RUPRECHT
}

From the Department of Neurology, Technical University of Munich, Munich, Germany

SUMMARY A study of muscles of the dystrophic mouse has failed to substantiate earlier claims that these muscles were especially resistant to fatigue in vitro or that fast muscles are preferentially damaged. It has been found that the fast muscle selected for previous studies is very often unable to withstand isolation in an organ bath if it is working, and both the difficulty in removing the normal gastrocnemius muscle intact and the need to trim it surgically contribute independently toward its deterioration in vitro. The smaller dystrophic gastrocnemius muscle is less liable to excision damage, is able to satisfy its resting metabolic needs in nutrient solution, and requires no damaging dissection, but is nevertheless unable to recover normally from fatigue. Using EDL and soleus muscles which are small enough to withstand isolation in vitro, no differences are found between fatigue patterns of normal and dystrophic specimens. Responses to rest, $\mathrm{KCl}$, and $2 \mathrm{mM}$ caffeine are also quite similar, and the only distinguishing biomechanical characteristic we have found in dystrophic mouse muscle is a weaker contraction and a longer total twitch time.

It has been reported, and apparently not widely disputed, that the gastrocnemius muscle from mice with a form of hereditary muscular dystrophy is much more resistant to fatigue than that from a normal mouse (Sandow and Brust, 1958, 1962; Eberstein and Sandow, 1963, Hinterbuchner, Angyan, and Hirsch, 1966). There is nothing in the well-known morphological or biochemical abnormalities of the dystrophic muscle cell which could be expected to confer such remarkable durability, and it is very difficult to reconcile the findings in vitro with either clinical experience or the motor performance of the afflicted mice. During the course of experiments with the same type of dystrophic mice and controls we have observed that widely divergent fatigue patterns may be recorded in different muscles from the same animal, depending upon the conditions of the experiment, and we have therefore re-examined in both slow and fast muscles the question of relative preservation of strength in muscular dystrophy.

\section{METHODS}

All experiments were performed in vitro on muscles removed from the hind limbs of mice. Twelve dys- trophic mice of the strain $d d y 129^{1}$ and 30 normal controls of similar age and weight were used. All the animals were from 8 to 12 weeks of age. The muscles were removed during ether anaesthesia with the assistance of a watch-maker's loupe and were tested in a specially constructed organ bath having two separate force transducers attached. The bath arrangement permitted a pair of muscles to be studied simultaneously, usually a slow and a fast muscle from the same animal. Muscles from both hind limbs were often tested in the same experiment, and then either both slow muscles or both fast muscles were examined together. The temperature of the bath was controlled by means of a water jacket and was maintained within $1.5^{\circ} \mathrm{C}$ during an experiment. The range of temperatures selected in all experiments was $29 \pm 1 \cdot 5^{\circ} \mathrm{C}$.

The muscles were removed as quickly as possible and were equilibrated at room temperature for at least 20 minutes before testing in vigorously oxygenated solution of the composition described by Elmqvist and Quastel (1965). Before mounting, the soleus muscles were carefully teased away from the under surface of the gastrocnemius muscle under a dissecting microscope, and, in the early experiments, the latter muscle was then gently separated into two or more separate bundles. Though great care was

1 Jackson Laboratory, Bar Harbor, Maine, U.S.A. 
taken in the original muscle excision, microscopic examination of the smaller bundles of the gastrocnemius muscle usually showed that there were large numbers of fibres that had been transected just below the very short tendon of origin. In a few cases it was felt that the muscle had been removed with the heads of origin intact, but then it was always found that many fibres had been torn or cut in the process of separating the whole muscle into smaller bundles. The smaller, flatter, dystrophic gastrocnemii were much easier to remove, as the heads of origin tended to be flat bands easily accessible deep in the popliteal fossa, and it was even possible in some of these muscles to excise a clearly identifiable piece of proximal tendon. Further, because of their reduced weight and volume, the dystrophic muscles needed no trimming to remain viable in the organ bath.

Because of the difficulties in obtaining truly comparable specimens, the gastrocnemius preparation was then rejected after the initial experiments, except as a vehicle for the soleus, and the extensor digitorum longus (EDL) was used as the fast muscle. The EDL was very nearly the same weight and shape as the soleus muscle from the same animal and so lent itself nicely to an additional comparison between slow and fast muscles. In several experiments the fatigue patterns of EDL and a relatively small bundle of gastrocnemius muscle from the same normal animal were compared and, in two dystrophic animals, a subdissected gastrocnemius bundle from one leg was tested in the same bath with the whole gastrocnemius muscle from the other.

Recording was by means of individual transducer units, each containing a strain gauge (Phillips PR 9810F) which was part of a separate bridge circuit. The output of these instruments was linear through the tension range of the test muscle (up to $80 \mathrm{~g}$ ) and was calibrated with known weights during every experiment. Since the transducers allowed a displacement of about $2 \mathrm{~mm} / 100 \mathrm{~g}$ of force, the muscles were not tested under truly isometric conditions. However, exactly the same recording technique was used for all the 85 muscles examined. The tension records were obtained with a direct-writing, multichannel oscillograph with a flat frequency response up to $500 \mathrm{~Hz}^{2}$ This instrument gave very satisfactory and continuous records of serial twitch and tetanus responses but did not permit detailed analysis of tension rise times. Total twitch times were therefore measured from onset to base line return. Both muscles lay across large silver electrode bars of about $1 \mathrm{~mm}$ diameter and were stimulated by means of a constant current/constant voltage stimulator. ${ }^{3}$

\footnotetext{
2 Elema-Sshonander Mingograf 8, Siemens, Germany.

3 Multistim, Disa Elektronik, Denmark.
}

The preparations were not curarized. Rectangular electrical pulses of $0.5 \mathrm{msec}$ duration and $40 \mathrm{~V}$ amplitude were delivered at either 1 or $100 \mathrm{~Hz}$. Higher tetanic stimulation frequencies did not give consistent increases in force at $29^{\circ} \mathrm{C}$. After setting the transducers so that the twitch responses were maximal, the muscles were carried through a stimulation programme designed to test certain aspects of fatigue. Sample twitches and tetani were first obtained while the muscles were fresh, and then stimuli at $1 \mathrm{~Hz}$ were continued, interrupted every four to five minutes by tetani of from 400 to 1,000 impulses each, until the responses fatigued and became too small to measure accurately. With the dystrophic muscles the measurement end-point was often reached more quickly, as the responses tended to be of lower amplitude to start with. The total stimulation programme was much more prolonged than that used by earlier workers, extending in several cases to over 10,000 impulses. After the fatigue programme all muscles were then tested sequentially for recovery with rest, ability to recover after a $\mathrm{KCl}$ induced contracture, and for the ability to respond to $2 \mathrm{mM}$ caffeine.

Measurements were made of the initial twitch and tetanus responses and thereafter at various poine 0 from 100 to 500 impulses apart in the 'run-down $\frac{1}{2}$ Tetanus:twitch ratios were calculated from the highest values for each, and the first measurements of twitch parameters were always made with fres muscles before the first tetanus had been deliverec Total twitch time measurements were then repeate at from 2,000-3,000 impulses. The twitch fatigue co curves of the muscles were all plotted simply as a fraction of the first and displayed as a separate group for each type of preparation. In order to be able to compare results with those of other workers, however, relative twitch values were specifically tabulated at 1,200-2,000 impulses. Relative tetanus fatigue was plotted at 5,000-5,200 impulses. To test the effects of rest, $\mathrm{KCl}$, and caffeine, the maximum twitch and tetanus tensions (as well as the fractional decay of tension within each tetanus) of the last responses before each change were compared with those some minutes later. Since the rest periods, $\mathrm{KCl}$, or caffeine were given at various times after the beginning of an experiment, the responses recorded were always those of a partly fatigued muscle, but the aim of these experiments was to compare the recuperative powers in the control and diseased $\frac{}{3}$ fibres. The muscles selected for comparison were $D$ those in which the test of interest had been made at nearly the same point on the fatigue curve, or after $N$ nearly the same total number of impulses. At the end of the experiment the tendons and all traces of fat $N$ were removed from each muscle under a dissecting $\omega$ 
microscope, and, after a single blotting, the muscles were weighed.

\section{RESULTS}

RELIABILITY OF GASTROCNEMIUS AS TEST MUSCLE The initial experiments were designed to test whether muscle as large as the normal gastrocnemius muscle could be kept in good condition in vitro at $30^{\circ} \mathrm{C}$. From these pilot studies it became clear that the whole normal gastrocnemius muscle was not a suitable specimen for prolonged study, and, though trimming occasionally produced a smaller gastrocnemius bundle which contracted well, the overall effect was not satisfactory, as can be seen in Fig. 1. The average, intact, normal gastrocnemius muscle weighed $148 \cdot 2 \pm 5.3 \mathrm{mg}$ (18 specimens), while the severely dystrophic muscles weighed only $23 \cdot 4 \pm$
$8.5 \mathrm{mg}$ (17 specimens). When the subdissected normal specimen was about one-third the volume of the whole it did no better at all in terms of its fatigue pattern, and it was only when it was possible to remove intact a very small piece (about $1 / 10$ of the whole) that the shape of the curve improved significantly. The specimens marked $\bigcirc(12.5 \mathrm{mg})$ and $(60 \mathrm{mg})$ in the Figure illustrate this point and should be compared with $\triangle$, a typical whole, dystrophic gastrocnemius muscle $(21.5 \mathrm{mg})$. What was of interest was that, while the whole dystrophic gastrocnemius muscle maintained its tension better than the usual whole normal muscle, the subdissected dystrophic muscle $(3 \cdot 2 \mathrm{mg})$ behaved very much like the trimmed normal and failed more rapidly than when it was left intact ( $\square$ in Fig. 1). It thus appeared that both large volume and surgical trimming adversely affected all

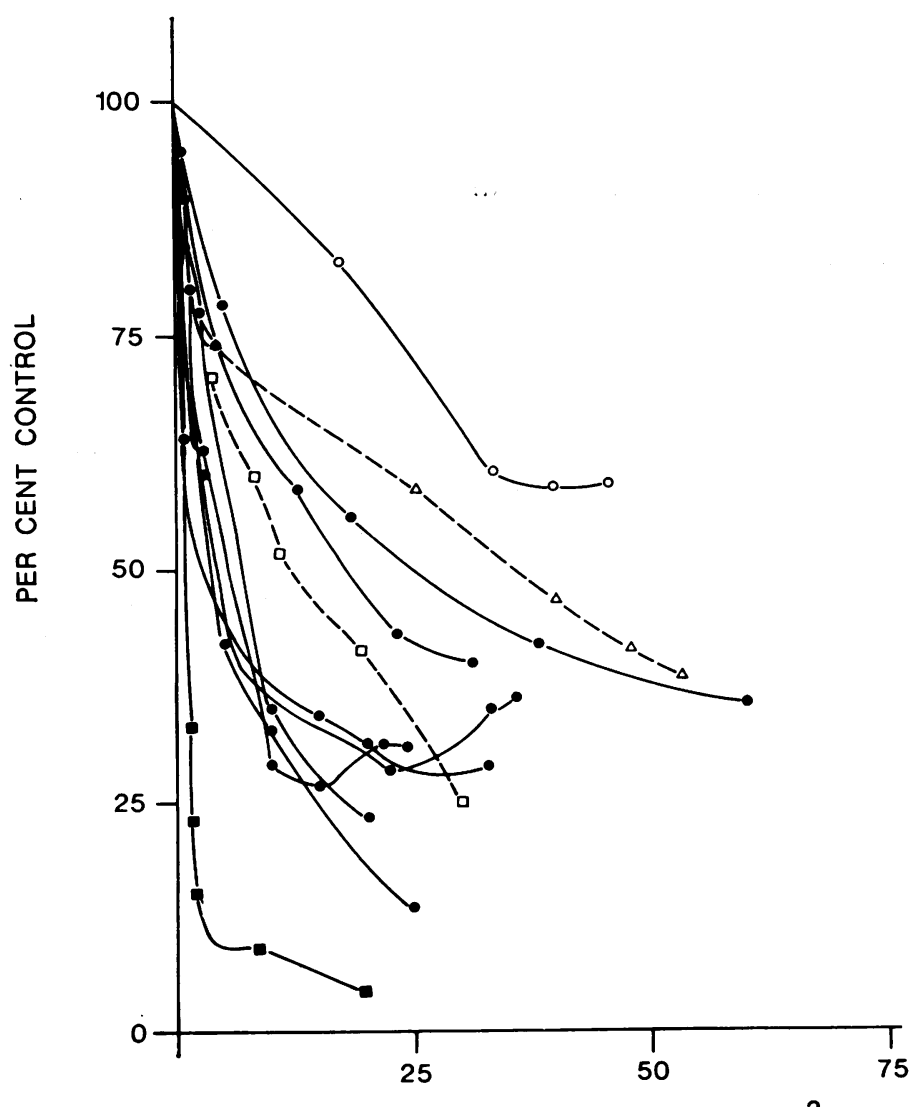

NO. OF IMPULSES $\times 10^{2}$
FIG. 1. Evidence of unsuitability of gastrocnemius as test preparation. Curves showing very rapid mechanical deterioration of both normal and dystrophic muscles if they were surgically damaged or weighed more than about 15-20 mg. Dashed traces are from dystrophic specimens, uninterrupted traces from normals. Filled circles, , from whole, normal gastrocnemeii, average weight about $148 \mathrm{mg}$. Filled squares, $\square$, from a normal gastrocnemius surgically trimmed to $60 \mathrm{mg}$. Open circles, $\bigcirc$, from normal specimen trimmed to $12.5 \mathrm{mg}$ without microscopic evidence of damage. Triangles, $\triangle$, from another dystrophic muscle trimmed to $3 \cdot 2 \mathrm{mg}$ and with some surgically damaged fibres. 


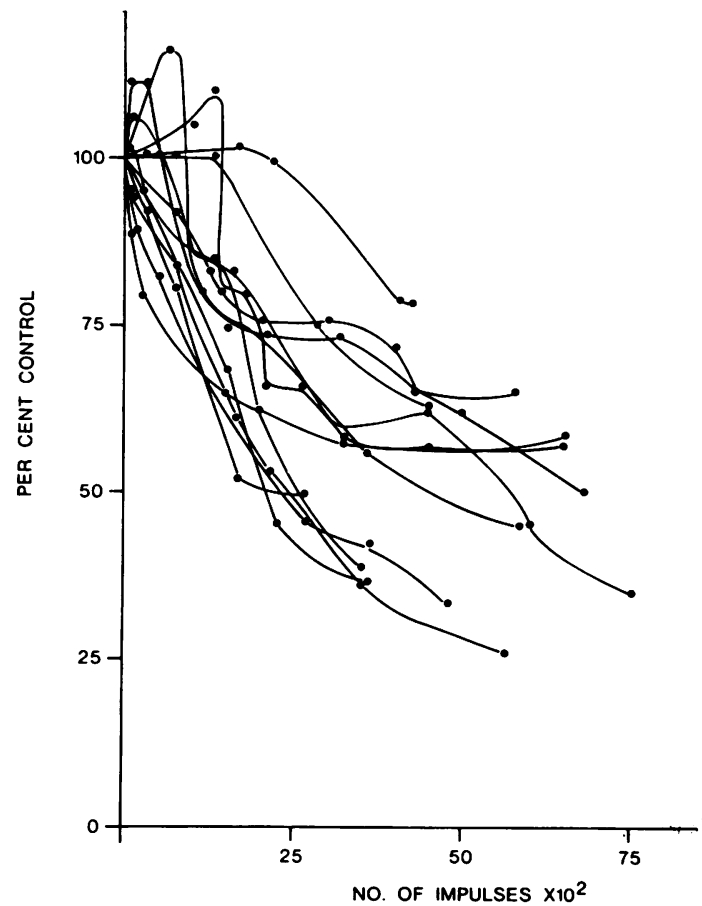

(a)

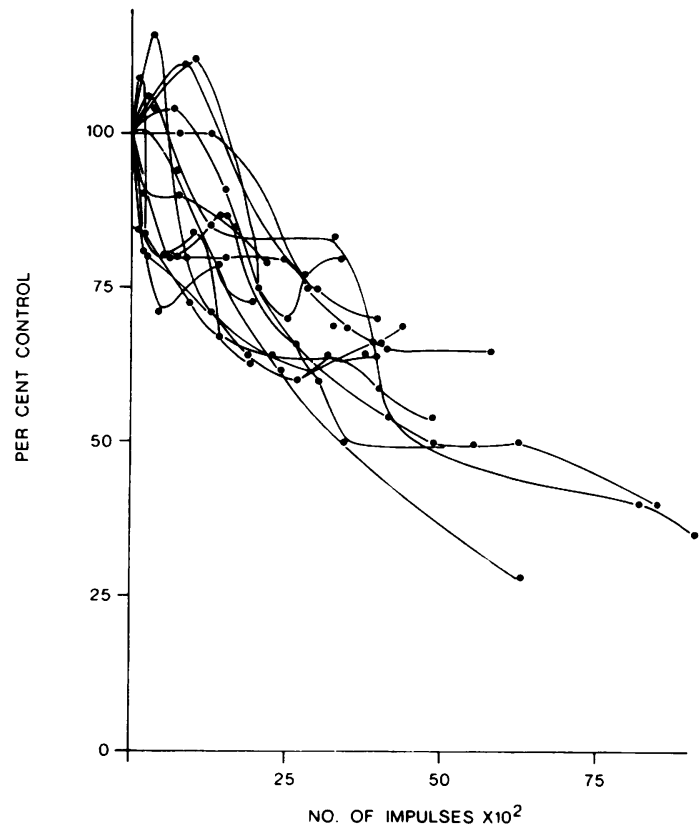

(b)

FIG. 2. Relative fatiguability of intact, fast muscles in normal and dystrophic mice. (a) Fatigue curves of several normal EDL muscles; (b) same for dystrophic EDL muscles. Note occasional positive treppe phenom- 0 응 enon in both groups. Stimulation at $1 \mathrm{~Hz}$. Temperature $28.5-30 \cdot 0^{\circ} \mathrm{C}$. Each curve fitted by eye to plots of value from a single muscle.

muscles under the conditions of our experiments.

Additional evidence of unsuitability of the gastrocnemius was obtained after the muscles' twitch tensions had dropped to about one half of their original values. In neither a normal whole gastrocnemius muscle nor a trimmed bundle was there the slightest recovery with 1025 minutes' rest, and there was either a very tiny or no response to both isotonic $\mathrm{KCl}$ and to $2 \mathrm{mM}$ caffeine. Further, with repeated stimulation there was no shortening of contraction and relaxation times in any gastrocnemius specimen. In fact, the tetanus rise and fall time in these preparations increased slowly until the muscle became exhausted. These results are to be contrasted with the partly reversible post-fatigue effects in the smaller extensor digitorum longus and soleus muscles (see below) and are identical with responses of muscles intentionally damaged before testing. Comparisons between the EDL from one leg of a normal mouse with the partly dissected or whole gastrocnemius muscle from the other revealed that the smaller muscle fatigued much less rapidly and that it could clearly recover after a partial run-down. The divergence of fatigue curves in these two normal muscles was identical with that reported by Sandow and Brust (1962) for dystrophic versus normal gastrocnemii.

COMPARISON OF FAST MUSCLES IN GOOD CONDITION Since the gastrocnemius muscle would not provide reliable data, the comparison between fast muscles was made with the extensor digitorum longus muscle (EDL) in the remaining animals. In the groups of curves of Fig. $2 a$ and Fig. $2 b$ it can be seen that the EDL muscles from the control and dystrophic animals did not show significantly different behaviour during long runs of 
TABLE 1

MECHANICAL PROPERTIES AND WEIGHTS OF NORMAL AND DYSTROPHIC MUSCLES AT 29-30 $\mathrm{C}$

\begin{tabular}{|c|c|c|c|c|c|c|}
\hline \multirow[t]{2}{*}{ Muscle } & \multicolumn{2}{|c|}{ Total twitch time (msec) } & \multirow[t]{2}{*}{$n$} & \multirow{2}{*}{$\begin{array}{c}\text { Average } \\
\text { weight } \\
(\mathrm{mg})\end{array}$} & \multirow{2}{*}{$\begin{array}{c}\text { Maximum } \\
\text { tetanus tension } \\
(\mathrm{g} / \mathrm{g})\end{array}$} & \multirow{2}{*}{$\begin{array}{c}\text { Tetanus } \\
\text { twitch } \\
\text { ratio* }\end{array}$} \\
\hline & $10-500$ impulses & 2,000-3,000 impulses & & & & \\
\hline $\begin{array}{l}\text { Normal EDL } \\
\text { Normal soleus }\end{array}$ & $\begin{array}{l}39 \\
96\end{array}$ & $\begin{array}{l}33 \\
86\end{array}$ & $\begin{array}{l}8 \\
8\end{array}$ & $\begin{array}{l}8 \cdot 6 \\
6 \cdot 5\end{array}$ & $\begin{array}{r}771 \\
1,157\end{array}$ & $\begin{array}{l}3 \cdot 0 \\
5 \cdot 4\end{array}$ \\
\hline $\begin{array}{l}\text { Dystrophic EDL } \\
\text { Dystrophic soleus }\end{array}$ & $\begin{array}{r}48 \\
132\end{array}$ & $\begin{array}{r}38 \\
109\end{array}$ & $\begin{array}{l}10 \\
14\end{array}$ & $\begin{array}{l}4 \cdot 0 \\
3 \cdot 8\end{array}$ & $\begin{array}{l}667 \\
893\end{array}$ & $\begin{array}{l}4.9 \\
6.7\end{array}$ \\
\hline
\end{tabular}

* From highest initial responses in fresh muscles.

TABLE 2

RELATIVE TWITCH AND TETANUS TENSION DECAYS IN NORMAL AND DYSTROPHIC MUSCLE

\begin{tabular}{|c|c|c|c|c|c|c|c|c|c|}
\hline \multirow{2}{*}{$\begin{array}{l}\text { Muscle type } \\
\begin{array}{l}\text { No. impulses } \\
\text { given }\end{array}\end{array}$} & \multicolumn{2}{|c|}{ Dystrophic EDL } & \multicolumn{2}{|c|}{ Normal EDL } & \multicolumn{2}{|c|}{ Dystrophic soleus } & \multicolumn{2}{|c|}{ Normal soleus } & \multirow{2}{*}{$\begin{array}{c}\begin{array}{c}\text { Normal } \\
\text { gastrocnemius } \\
(\text { all })\end{array} \\
2,000\end{array}$} \\
\hline & 1,200 & 2,000 & 1,200 & 2,000 & 1,200 & 2,000 & 1,200 & 2,000 & \\
\hline $\begin{array}{l}\% \text { control } \\
\text { Difference } \\
n\end{array}$ & $\begin{array}{c}84 \cdot 8 \pm 3 \cdot 3 \\
14\end{array}$ & $75 \cdot 0 \pm 8 \cdot 8$ & $\begin{array}{c}81 \cdot 4 \pm 4 \cdot 8 \\
P>0 \cdot 1 \\
13\end{array}$ & $\begin{array}{c}67 \cdot 3 \pm 3 \cdot 8 \\
P>0 \cdot 1\end{array}$ & $\begin{array}{c}75 \cdot 1 \pm 4 \cdot 8 \\
10\end{array}$ & $70 \cdot 3 \pm 4 \cdot 7$ & $\begin{array}{c}70 \cdot 4 \pm 2 \cdot 8 \\
P>0 \cdot 1 \\
11\end{array}$ & $\begin{array}{c}67 \cdot 8 \pm 3.9 \\
P>0 \cdot 1\end{array}$ & $\begin{array}{c}26.7 \pm 3 \cdot 2 \\
P<0.01^{*} \\
9\end{array}$ \\
\hline $\begin{array}{l}\text { No. impulses } \\
\% \text { control } \\
\text { Difference }\end{array}$ & \multicolumn{2}{|c|}{$\begin{array}{c}5,200 \\
72 \cdot 6 \pm 2 \cdot 1\end{array}$} & \multicolumn{2}{|c|}{$\begin{array}{c}5,200 \\
68 \cdot 5 \pm 4 \cdot 3 \\
P>0 \cdot 05\end{array}$} & \multicolumn{2}{|c|}{$\begin{array}{c}5,200 \\
92 \cdot 1 \pm 4 \cdot 8\end{array}$} & \multicolumn{2}{|c|}{$\begin{array}{c}5,000 \\
82 \cdot 9 \pm 3 \cdot 1 \\
P>0.05\end{array}$} & $\begin{array}{r}2,500 \\
<10\end{array}$ \\
\hline
\end{tabular}

* Compared with either normal or dystrophic EDL.

stimuli. It should be emphasized that the dystrophic specimens were clearly affected by the disease, their weight being appreciably less than normal and their strength definitely reduced, as shown in Table 1. The data in the curves of Fig. 2 can be compared more directly with those in earlier reports by reference to Table 2, where averaged values are given for twitch and tetanus fatigue at points very close to those selected by other workers (Sandow and Brust, 1962). We did not find stabilization, or a plateau, of relative twitch and tetanus force values at a very low level after only 1,000 to 2,000 impulses in any muscle other than the gastrocnemius (whole, normal), though the stimulation programme was extended to 10,000 impulses in some cases. The values in Table 2 confirm that, when the EDL muscle is used, the fatigue patterns of normal and dystrophic muscles are not significantly different.

COMPARISON OF SLOW AND FAST MUSCLES Since the properties of two muscles could easily be compared simultaneously in our experimental set-up, comparisons were next made of the relative twitch and tetanus tension decay curves in paired fast and slow muscles from both normal and diseased animals. Further, the fatigue pattern of the normal soleus muscle was compared with that of the dystrophic, as shown in Fig. 3. It can be seen that the fatigue pattern of slow muscles in the dystrophic mouse is also indistinguishable from normal, as had earlier been found by Brust (1966). Table 2 shows that, while the average twitch response of both normal and dystrophic soleus muscle fell quickly to a slightly lower level than the twitches of EDL (at 1,200 impulses), the slow muscles from both test groups were nevertheless able to achieve a higher fraction of their original tetanus tension after 5,000 impulses. The run-down of relative twitch tension in dystrophic soleus muscle over the entire stimulation programme was about the same as that of the EDL muscles from either group, and there was thus no evidence of selective involvement of the fast fibres. 


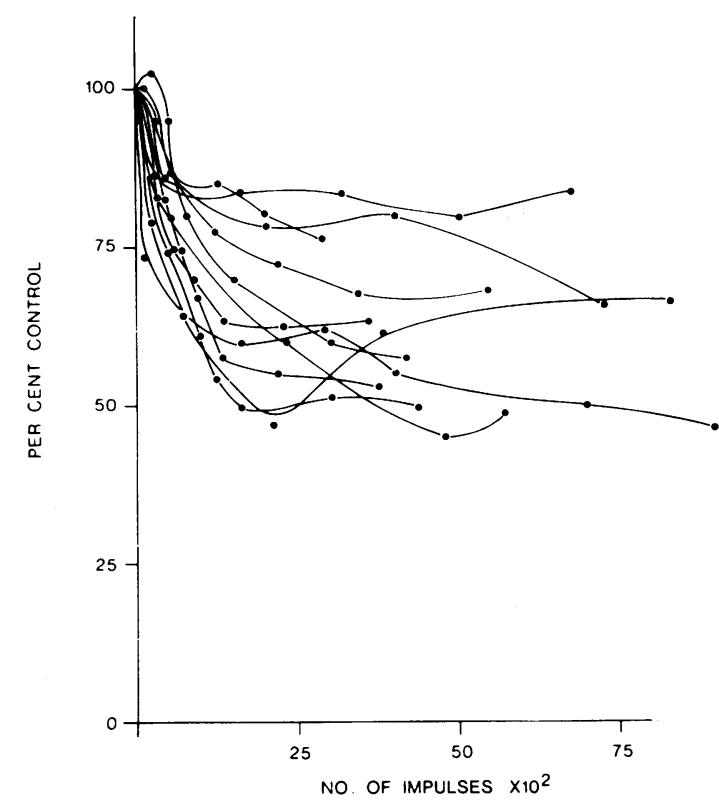

(a)

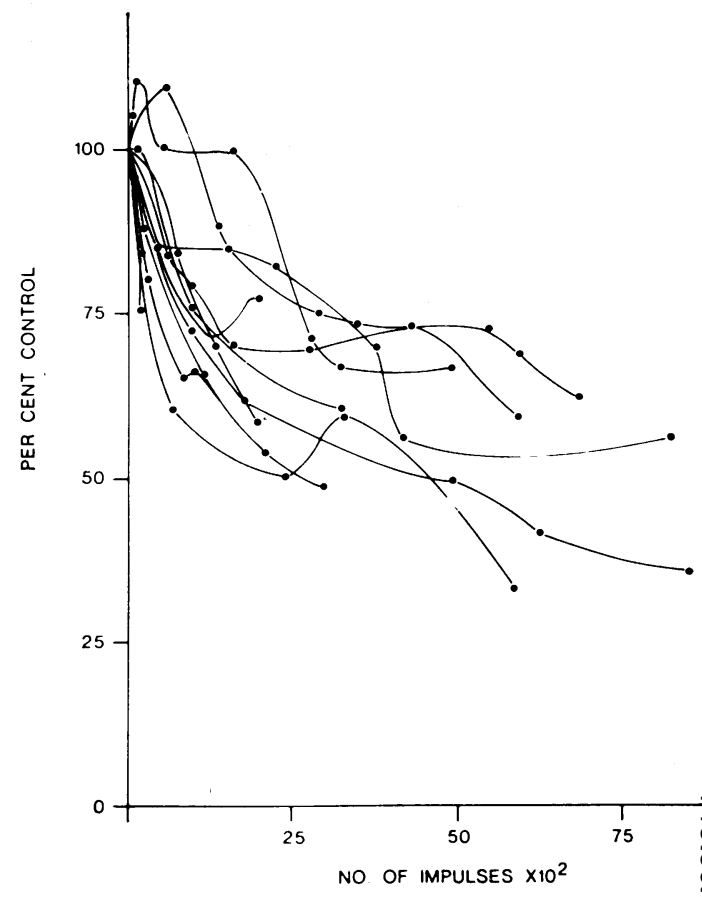

(b)

FIG. 3. Relative fatiguability of intact, slow muscles from normal and dystrophic mice. (a) Decay of twitch tension in several normal soleus muscles; (b) same in dystrophic specimens. Temperature $28.5-30 \cdot 0^{\circ} \mathrm{C}$. Curve obtained as in Fig. 2.

TABLE 3

EFFECTS OF REST ON PARTLY FATIGUED NORMAL AND DYSTROPHIC MUSCLES (SEE TEXT)

\begin{tabular}{|c|c|c|c|c|c|c|c|c|}
\hline Type muscle & $\begin{array}{c}\text { Intra-tetanus } \\
\text { change before } \\
(\% / 100 \text { impulses })\end{array}$ & $n$ & $\begin{array}{l}\text { Average } \\
\text { rest } \\
(\text { min })\end{array}$ & $\begin{array}{c}\text { Number impulses } \\
\text { before rest } \\
\text { (average) }\end{array}$ & $\begin{array}{l}\text { Intra-tetanus } \\
\text { change after } \\
(\% / 100 \text { impulses })\end{array}$ & Net & $\begin{array}{l}\text { Peak tetanus } \\
\text { change }(\%)\end{array}$ & $\begin{array}{l}\text { Peak twitch } \\
\text { change }(\%)\end{array}$ \\
\hline $\begin{array}{l}\text { Normal EDL } \\
\text { Normal soleus }\end{array}$ & $\begin{array}{l}-2 \cdot 2 \\
+1 \cdot 3\end{array}$ & $\begin{array}{l}17 \\
12\end{array}$ & $\begin{array}{l}11 \\
11\end{array}$ & $\begin{array}{l}2,800 \\
3,300\end{array}$ & $\begin{array}{l}+3 \cdot 4 \\
+0 \cdot 2\end{array}$ & $\begin{array}{l}+5 \cdot 6 \\
-1 \cdot 1\end{array}$ & $\begin{array}{l}-3 \\
+3\end{array}$ & $\begin{array}{r}+5 \\
+22\end{array}$ \\
\hline $\begin{array}{l}\text { Dystrophic EDL } \\
\text { Dystrophic soleus }\end{array}$ & $\begin{array}{l}-1 \cdot 1 \\
+0.05\end{array}$ & $\begin{array}{l}13 \\
11\end{array}$ & $\begin{array}{l}14 \\
12\end{array}$ & $\begin{array}{l}3,000 \\
2,750\end{array}$ & $\begin{array}{l}+0.5 \\
-0.02\end{array}$ & $\begin{array}{l}+1.6 \\
-0.07\end{array}$ & $\begin{array}{l}-2 \\
-3\end{array}$ & $\begin{array}{r}-14 \\
-2\end{array}$ \\
\hline
\end{tabular}

COMPARISON OF RECOVERY PATTERNS Although the dystrophic fibres showed no mechanical efficiency change that distinguished them in either direction from normal fibres in the relative 'run-down' experiments, it was obvious that their contractions were weaker, gramme for gramme, from the start. The question thus arose whether the diseased fibres were weak because they were perpetually in some sort of 'fatigue' state in terms of energy metabolism, active ion 을 transport, etc. Three parameters were selected in attempts to answer this question: First, the muscles' ability to repair whatever mechanism had fatigued by means of a period of rest; second, their ability to re-establish a critical membrane potential and electrical excitability 
TABLE 4

POTASSIUM CONTRACTURES IN NORMAL AND DYSTROPHIC MUSCLE

\begin{tabular}{|c|c|c|c|c|c|c|c|c|}
\hline \multirow[t]{2}{*}{ Muscle type } & \multicolumn{4}{|c|}{ Initial response } & \multicolumn{4}{|c|}{ Recovery } \\
\hline & $\begin{array}{l}\text { Average no. } \\
\text { impulses and } \\
\text { range }\end{array}$ & $\begin{array}{l}\text { Average time } \\
\text { to peak and } \\
\text { range }(\mathrm{sec})\end{array}$ & $\begin{array}{l}\text { Average half } \\
\text { relaxation } \\
\text { time and } \\
\text { range (sec) }\end{array}$ & $\begin{array}{c}\text { Reactive con- } \\
\text { tracture } \\
\text { strength }(\% \\
\text { last tetanus) } \\
\text { and range }\end{array}$ & $\begin{array}{l}\text { Percent last } \\
\text { twitch and } \\
\text { range }\end{array}$ & $\begin{array}{l}\text { Percent last } \\
\text { tetanus and } \\
\text { range }\end{array}$ & $\begin{array}{l}\text { Interval } \\
(\min )\end{array}$ & $n$ \\
\hline Normal EDL & $\begin{array}{c}6,200 \\
(2,500-11,600)\end{array}$ & $\begin{array}{c}6 \\
(4-8)\end{array}$ & $\begin{array}{c}14 \\
(10-22)\end{array}$ & $\begin{array}{c}27 \\
(11-36)\end{array}$ & $\begin{array}{c}76 \\
(32-114)\end{array}$ & $\begin{array}{c}45 \\
(23-77)\end{array}$ & 5 & 7 \\
\hline Normal soleus & $\begin{array}{c}6,200 \\
(2,500-11,600)\end{array}$ & $\begin{array}{c}8 \\
\left(4^{-18}\right)\end{array}$ & $\begin{array}{c}21 \\
(10-41)\end{array}$ & $\begin{array}{c}55 \\
(35-90)\end{array}$ & $\begin{array}{c}48 \\
(46-92)\end{array}$ & $\begin{array}{c}51 \\
(41-87)\end{array}$ & 5 & 8 \\
\hline Dystrophic EDL & $\begin{array}{c}5,600 \\
(2,200-11,000)\end{array}$ & $\begin{array}{c}10 \\
(5-18)\end{array}$ & $\begin{array}{c}12 \\
(5-18)\end{array}$ & $\begin{array}{c}32 \\
(15-60)\end{array}$ & $\begin{array}{c}60 \\
(30-92)\end{array}$ & $\begin{array}{c}61 \\
(35-100)\end{array}$ & 5 & 12 \\
\hline Dystrophic soleus & $\begin{array}{c}5,600 \\
(2,200-11,000)\end{array}$ & $\begin{array}{c}19 \\
(12-51)\end{array}$ & $\begin{array}{c}20 \\
(11-40)\end{array}$ & $\begin{array}{c}43 \\
(17-66)\end{array}$ & $\begin{array}{c}69 \\
(23-85)\end{array}$ & $\begin{array}{c}45 \\
(19-80)\end{array}$ & 5 & 12 \\
\hline
\end{tabular}

after a sustained depolarization, and, thirdly, their ability to respond to a potentiating or 'defatiguing' drug.

As shown in Table 3, recovery with rest alone was compared in normal and dystrophic EDL as well as in normal and dystrophic soleus muscle. The very complex changes that followed the rest period can be considered in terms of three basic factors; a change in the peak tension available during the tetanus, a changed ability to sustain that tetanus tension, or a change in the maximum twitch tension. These measurements cannot give any direct information about the links between excitation and contraction or about the intensity of the active state in the contractile proteins themselves because, in a partly fatigued, multifibre preparation, the changes after rest may be entirely the result of recruitment. In any case, the normal muscle seems to do slightly better than the dystrophic (certainly not the reverse) and may have some type of greater reserve which is not defined by the test.

The $\mathrm{KCl}$ effects and recovery are illustrated in Table 4, the data on the left indicating the fatigued muscles' ability to respond, those on the right, their ability to recover excitability after five minutes again in normal nutrient solution. In each of the partly fatigued muscles the strength of the contracture after $\mathrm{KCl}$ was but a fraction of that generated by the last tetanus. Such a finding is not unexpected in view of the fact that, even in the smallest specimens (2$3 \mathrm{mg}$ ), diffusion lag precluded simultaneous depolarization of all the fibres, and it is clear that, in the multifibre preparation, the $\mathrm{KCl}$ contracture cannot be used to distinguish failure of excitation-contraction coupling, or surface causes of fatigue, from disturbances in the contractile proteins themselves (Eberstein and Sandow, 1963). The data show that the $\mathrm{KCl}$ contracture was weakest in the normal fast muscles, the normal EDL achieving only about one-quarter the force of a tetanus given electrically at the same point on the run-down curve. The slow muscles of both dystrophic and normal animals gave proportionally stronger responses. With regard to the time course of the contractures in all the muscles, it must be emphasized that the $\mathrm{KCl}$ exposure was never more than 60 seconds, after which the bath was very thoroughly washed. All the muscles had, moreover, already begun to relax by the time the $\mathrm{KCl}$ was removed, and so the withdrawal of the ion presumably had little to do with the relaxation. It can be seen that slow muscles give more prolonged contractures with slower rise times than those of fast muscles in both normal and dystrophic animals, and that the development of contracture tension in dystrophic soleus muscle is slowest of all. The fast muscles of normal mice gave a quicker rise to peak contracture tension than dystrophic muscles, though the relaxation times were about the same.

The ability of the various muscles to repolarize to some critical value was estimated by recording, at a standard interval, the relative return of twitch and tetanus tension. The rate at which the membranes would approach normal excitability 
would, of course, be influenced greatly by the length of their exposure to the high $\left[\mathrm{K}^{+}\right]$ solution (Milligan and Edwards, 1965), and in this connection it is important to emphasize that all muscles were treated in exactly the same way. Taking exposure time as equal in all experiments, probably the most significant factor in the electrophysiological recovery would be the degree to which actual concentration changes across the membrane had progressed during the depolarization. The aim of this part of the experiments was to try to learn if a brief period in pure, isotonic $\mathrm{KCl}$ would cause major 'leaks' in a diseased fibre, after which energy-dependent ion pumping would be needed to restore excitability. If such were the case, the dystrophic muscles would require more time to recover or would not recover at all.

The data in Table 4 indicate that the slow and fast muscles from both dystrophic and normal mice can recover from one half to three-quarters of their contracture strength shortly after $\mathrm{KCl}$ depolarization and that the normal seems to have no particular advantage. Statistical methods could not be applied to either twitch or tetanus recovery data as the $\mathrm{KCl}$ tests were not all made at the same points on the fatigue curves of the various muscles. It was concluded that the diseased muscle had not suffered either a greater disturbance of its internal ionic milieu or any difficulty with active ion transport and restoration of membrane polarization after $\mathrm{KCl}$ exposure.

The caffeine experiments can be summarized by saying that every muscle was exposed to a $2 \mathrm{mM}$ concentration of the alkaloid at some point in the 'run-down' programme. Sometimes the drug was applied before $\mathrm{KCl}$ and sometimes after, and, in all cases, there were impressive changes. Within a few seconds both twitch and tetanus tensions had begun to increase, and, where the tension of the previously fatigued fast muscles had shown a tendency to decrease within a tetanus, or to rise very slowly to peak, the caffeine record usually showed a return to the original, stable pattern. The caffeine potentiation was about the same in normal and dystrophic fibres, and in neither group did a $2 \mathrm{mM}$ concentration produce a measurable contracture. On the other hand, twitch relaxation times were clearly prolonged in slow and fast muscles of both animal groups, and a tetanus after caffeine was followed by a post-tetanic contracture, most marked in the soleus muscle.

\section{DISCUSSION}

Since we have not been able to substantiate the claim that dystrophy confers on either fast or slow skeletal muscle an unusual resistance to fatigue it is essential to describe any technical or experimental variations which might account for the divergent findings. First, we have used a different muscle, because in a series of early experiments it became clear that neither a whole, nor a partially subdissected, normal gastrocnemius muscle could be kept in good condition in vitro. The smaller dystrophic gastrocnemius muscle, which could more easily be removed intact and which required no trimming to reduce its volume, performed better in terms of its relative fatiguability, but if a normal gastrocnemius specimen could be reduced to the same weight, approximately, as the soleus muscle withouteत injury, then that small bundle fatigued no more $\frac{\text { ? }}{\mathbb{D}}$ rapidly than the dystrophic muscle. The importance of injury in muscle performance was clearly shown for the dystrophic gastrocnemius muscle, which failed after subdissection just as quickly as the trimmed normal muscle. Even the intact, whole dystrophic gastrocnemius muscle showed a very limited ability to recover after 'run-down', and so it appeared that this relatively large muscle, too, was damaged irreversibly by long stimulation in vitro. Taken together, all these findings led us to conclude that no reliable data could be obtained from the gastrocnemius muscle and that what had previously been called rapid fatigue in relatively large pieces of normal muscle was in fact cell death.

All significant differences in relative fatiguability disappeared when smaller fast muscles from the two groups of animals were compared, and it was further observed that the fatigue patterns of the slow soleus muscles were indistinguishable.

Another point of experimental difference was that we used a higher temperature. There is no reason to suppose that this change biased results in the direction of better survival of muscle, as it is well known that higher temperatures cause earlier deterioration of muscles in vitro. Thirdly, 
we did not curarize our preparations. While it is theoretically possible to argue that, after each direct shock to the muscles there could have been repetitive, indirect activation of some fibres, which would then fatigue earlier, there is no obvious mechanism by which this phenomenon would have equalized the performance of the muscles. Furthermore, it is clear that indirect activation would very quickly have failed entirely under the conditions of our experiments.

No arguments can be made that the EDL muscle is not affected by the disease or that it does not represent the group of pale, fast muscles of the extremities. Its twitch time was, if anything, shorter than that of the gastrocnemius muscle, suggesting that it may be even freer of the admixture of type I fibres known to exist in the larger muscle (Wuerker, McPhedran, and Henneman, 1965; Dubowitz, 1968). A higher proportion of type II fibres in the EDL could hardly be expected to make it more resistant to fatigue during long trains of stimulation in vitro.

In certain other aspects of muscle behaviour our results also have not confirmed the findings of previous investigators. For example, we did not find that dystrophic muscle, though slower than normal at the beginning, responded to activity with a greater than normal increase of contraction and relaxation rates during repetitive stimulation (Sandow and Brust, 1962; Hinterbuchner et al., 1966). The diseased EDL did show longer total twitch times than the normal, but both responded with the same relative increases in the velocity of shortening and relaxing during the first 1,000 to 2,000 impulses. On the other hand, the whole or subdissected normal gastrocnemius muscle characteristically developed a progressive delay in both rise to peak tetanic tension and relaxation very soon after stimulation was begun and then quickly went on to irreversible exhaustion. This latter behaviour is typical of a damaged or anoxic muscle and does not suggest that the dystrophic fibres, by comparison, are especially resistant to stress.

In these experiments we have found far more similarity between the diseased and normal fibres than differences with the tests we have used, and we believe that the previously reported resiliency of dystrophic muscle, as well as the apparent greater vulnerability of fast fibres to the disease process (Brust, 1966) were both the result of an experimental artefact. Laying aside the paradoxical durability phenomenon, one still has the question how it can be that tissues so grossly deranged histologically as dystrophic muscle fibres can still function so much like the normal. One possibility is that the finding results from a major sampling error, the fibres responding to the present series of test being largely spared by the disease process, while the others have either not achieved development past rudimentary stages (Goldspink and Rowe, 1968) or have been replaced with fat or connective tissue.

The authors acknowledge with thanks the generous support of the Deutsche Forschungs Gemeinschaft and the Technical University of Munich and the facilities provided by Professor A. Struppler, Director of the Department of Neurology.

\section{REFERENCES}

Brust, M. (1966). Relative resistance to dystrophy of slow skeletal muscle of the mouse. American Journal of Physiology, 210, 445-451.

Dubowitz, V. (1968). Further studies on fibre types in skeletal muscle. In Research in Muscular Dystrophy, pp. 100-115. Proceedings of the Fourth Symposium on Current Research, 1968. Edited by members of the Muscular Dystrophy Group. Pitman: London.

Eberstein, A., and Sandow, A. (1963). Fatigue mechanisms in muscle fibres. In The Effects of Use and Disuse on Neuromuscular Functions, pp. 515-526. Edited by E. Gutmann and P. Hnik. Elsevier: Amsterdam.

Elmqvist, D., and Quastel, D. M. J. (1965). A quantitative study of end-plate potentials in isolated human muscle. Journal of Physiology, 178, 505-529.

Goldspink, G., and Rowe, R. W. D. (1968). The growth and development of muscle fibres in normal and dystrophic mice. In Research in Muscular Dystrophy, pp. 116-131. Proceedings of the Fourth Symposium on Current Research, 1968. Edited by members of the Muscular Dystrophy Group. Pitman: London.

Hinterbuchner, L. P., Angyan, A., and Hirsch, M. (1966). Effect of series of tetani on dystrophic and normal muscles of mouse. American Journal of Physiology, 211, 915-918.

Milligan, J. V., and Edwards, C. (1965). Some factors affecting the time course of the recovery of contracture ability following a potassium contracture in frog striated muscle. Journal of General Physiology, 48, 975-983.

Sandow, A., and Brust, M. (1958). Contractility of dystrophic mouse muscle. American Journal of Physiology, 194, 557563.

Sandow, A., and Brust, M. (1962). Effects of activity on contractions of normal and dystrophic mouse muscles. American Journal of Physiology, 202, 815-820.

Wuerker, R. B., McPhedran, A. M., and Henneman, E. (1965). Properties of motor units in a heterogeneous pale muscle (M. gastrocnemius) of the cat. Journal of Neurophysiology, 28, 85-99. 